\title{
Surfactant Behavior of Sodium Dodecylsulfate in Deep Eutectic Solvent Choline Chloride/Urea
}

\author{
T. Arnold,,$^{\dagger}{ }^{\dagger}$ A. J. Jackson, ${ }^{\ddagger, \S}$ A. Sanchez-Fernandez, ${ }^{\ddagger, \|}$ D. Magnone, ${ }^{\dagger}$ A. E. Terry, ${ }^{\perp}$ and K. J. Edler ${ }^{\|}$ \\ ${ }^{\dagger}$ Diamond Light Source, Harwell Campus, Didcot OX11 ODE, U.K. \\ ${ }^{\ddagger}$ European Spallation Source, Lund 221 00, Sweden \\ ${ }^{\S}$ Department of Physical Chemistry, Lund University, SE-221 00 Lund, Sweden \\ "Department of Chemistry, University of Bath, Claverton Down, Bath BA2 7AY, U.K. \\ ${ }^{\perp}$ ISIS Spallation Neutron Source, Harwell Campus, Didcot OX11 ODE, U.K.
}

Supporting Information

ABSTRACT: Deep eutectic solvents (DES) resemble ionic liquids but are formed from an ionic mixture instead of being a single ionic compound. Here we present some results that demonstrate that surfactant sodium dodecyl sulfate (SDS) remains surface-active and shows self-assembly phenomena in the most commonly studied DES, choline chloride/urea. X-ray reflectivity (XRR) and small angle neutron scattering (SANS) suggest that the behavior is significantly different from that in water. Our SANS data supports our determination of the critical micelle concentration using surface-tension measurements and suggests that the micelles formed in DES do not have the same shape and size as those seen in water. Reflectivity measurements have also demonstrated that the surfactants remain surface-active below this concentration. in Water

\section{INTRODUCTION}

The discovery of new solvents for amphiphile self-assembly aids in understanding the important solvent properties which enable this self-aggregation, allows the systems to be tuned for particular applications (via control of polarity, surface tension, viscosity, conductivity, refractive index, and thermal properties), and improves our understanding of the solvophobic effect to allow further development of useful self-organized materials. Micellization, particularly of nonionic surfactants in protic ionic liquids, has been the subject of several studies beginning in the $1980 \mathrm{~s}^{1}$ but with a recent upsurge in interest. ${ }^{2-7}$ At least 37 protic ionic liquids have been identified as solvents in which micellization can occur. ${ }^{6}$ However, the hygroscopic nature of ionic liquids and the frequent extremes of $\mathrm{pH}$ found in these solvents are not conducive to the long-term stability of surfactants in these media, and their expense and toxicity prevent their use in many applications.

Deep eutectic solvents (DES) are an alternative to ionic liquids with several potential advantages. In particular, they are easily prepared from cheap, nontoxic molecules and can be formed from biodegradable and biocompatible neutral species. DES resemble ionic liquids but are formed from an ionic mixture instead of being a single ionic compound. In deep eutectic solvents, the formation of a liquid at ambient temperatures relies on a large depression in freezing point coming from a favorable hydrogen bonding interaction between the constituents. The freezing-point depression is largest at the eutectic point and can be as much as $270{ }^{\circ} \mathrm{C} .{ }^{8} \mathrm{DES}$ share with

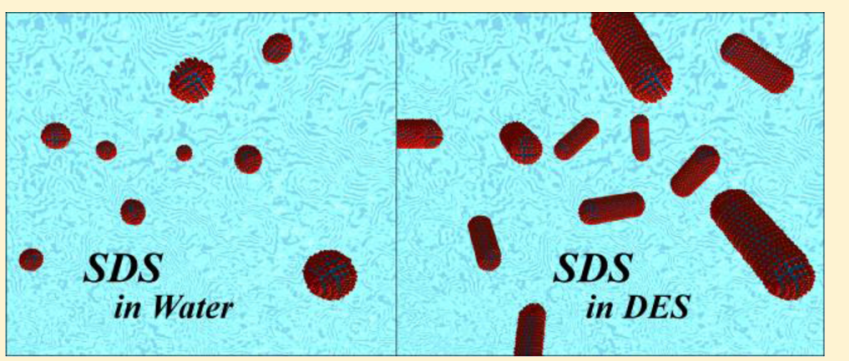
ionic liquids properties which make them highly desirable as green solvents; they have very low volatility, are generally nonflammable, and have a wider liquid temperature range than molecular solvents. DES in general have been shown to be good solvents for a range of inorganic salts ${ }^{9}$ and have been studied the most in the electroplating of metals such as zinc, ${ }^{10}$ silver, ${ }^{11}$ and aluminum. DES can also be used to create alloys ${ }^{12}$ and metal nanoparticles ${ }^{13}$ as well as in the processing of metal oxides. $^{14}$ DES have also been investigated for use in pharmaceutical applications ${ }^{15}$ and for selective extractions of, for example, high-value species from biomass ${ }^{16}$ and glycerol from biodiesel. ${ }^{1}$

In general most DES are composed of a quaternary ammonium halide salt mixed with metal salts or a hydrogenbond donor. The strong interaction of this donor with the halide ions stabilizes the liquid and results in the large depression of freezing point at the eutectic composition. The most studied series of DES are those prepared using choline chloride, which is a food additive (choline is an essential nutrient, usually grouped with the $\mathrm{B}$ vitamins), with one of many other species, including urea ${ }^{18}$ or $\mathrm{M}^{2+}$ ions such as $\mathrm{Zn}^{2+}{ }^{19}$ A wide range of other DES have also been identified, and their syntheses and properties have recently been reviewed by Zhang et al. ${ }^{20}$ This review summarizes what is known about

Received: July 14, 2015

Revised: November 4, 2015

Published: November 5, 2015 
the freezing points, density, viscosity, polarity, acidity, ionic conductivity, and surface tension for a range of different DES. Importantly, one of the most noticeable properties of many DES is high viscosity. This may result from many factors including the presence of an extensive hydrogen-bonding network, relatively large ion sizes, and electrostatic forces within the liquid.

Very recently it has been suggested that sodium dodecyl sulfate (SDS) shows some self-assembly phenomena in choline chloride/urea DES containing either water or cyclohexane. ${ }^{21}$ These authors presented surface tension and dynamic light scattering (DLS) measurements for a series of choline chloride/ urea solutions containing both SDS and water. Crucially they did not report any results for SDS in the pure DES, so we cannot be sure that the observed structures are micelles or that similar behavior would be observed in the absence of water. The DLS results presented indicate that the self-assembled structures are substantially larger than those observed in water, which is an interesting result. For most polar but nonaqueous solvents, SDS is found to form smaller micelles than for the same surfactant in water. ${ }^{22,23}$ This result in itself merits further investigation, but disappointingly these authors did not present any additional experimental evidence to refine the details of the observed structures. Typically DLS does not give information on particle shape since the calculations based on diffusion rates assume spherical objects. They did, however, present some data (surface tension, DLS, fluorescence spectroscopy, and smallangle X-ray scattering (SAXS)) on microemulsions formed by cyclohexane and the DES in the presence of SDS. They used this data to conclude that the solubility of cyclohexane in DES was improved by the presence of SDS. This was explained by the formation of a microemulsion, a conclusion that is consistent with the data presented. However, the interpretation of their SAXS data is unsatisfactory, and we shall discuss this further below.

In this study we have examined the relatively well studied DES based on choline chloride and urea (mixed in a 1:2 molar ratio). This system is probably the most studied of any DES and is therefore an obvious starting place for studies of the behavior of surfactants within DES. The role of water in these systems is also likely to be important for future applications, so this has also been briefly considered. The surfactant chosen for this work is sodium dodecyl sulfate, which is a representative anionic surfactant for which extensive data of its behavior in water already exists, for example, from surface tension, ${ }^{24,25}$ small-angle scattering, ${ }^{22,26}$ and reflectometry ${ }^{24,27,28}$ studies. We have performed small-angle neutron scattering (SANS) measurements to demonstrate the existence of micelles formed by SDS in a pure urea/choline chloride DES and to provide detail for the structure of these self-assembled systems. We have also verified that this surfactant is surface-active in the urea/ choline chloride mixture and have determined the structure of the adsorbed surfactant film at the air-water interface by means of X-ray reflectivity.

\section{EXPERIMENTAL SECTION}

Materials. We have used the following abbreviations for the materials used in this study: h-SDS and d-SDS are fully protonated and deuterated sodium dodecyl sulfate, respectively, and h-urea and d-urea are similarly fully protonated and deuterated urea. Finally h-ChCl refers to fully protonated choline chloride $\left(\left(\mathrm{CH}_{3}\right)_{3} \mathrm{NC}_{2} \mathrm{H}_{4} \mathrm{OH} \mathrm{Cl}\right)$, and $\mathrm{d}-\mathrm{ChCl}$ refers to the partially deuterated equivalent $\left(\left(\mathrm{CD}_{3}\right)_{3} \mathrm{NC}_{2} \mathrm{H}_{4} \mathrm{OH} \mathrm{Cl}\right)$. All protonated materials used were $\geq 98 \%$ pure and purchased from Sigma-Aldrich while the deuterated materials were purchased from QMX Laboratories (98\% deuteration, 99\% purity). The compounds were used without further purification since the ultimate applications for these systems are unlikely to use pure compounds. Similarly, although the samples have been kept in sealed bottles they are hydroscopic, so the precise water content of the samples is not known. There is no doubt that the presence of impurities will have some effect on the details of the behavior observed.

We have not attempted to control the humidity or water content during measurements but have in some cases monitored the behavior in DES solutions containing 5 wt \% water. It is potentially possible to measure the water content of the DES, but actually for practical reasons this is not straightforward. Sample preparation is done in a laboratory, and during this process and during subsequent measurements water is constantly being absorbed from the atmosphere. Therefore, it would be difficult to take a measurement of the water content at the crucial moment when it is being measured by another probe. As a result we have taken the approach of accepting a certain water content and have tried to assess whether this actually significantly changes the observed results. To do this we have determined the water content of several representative samples using the Karl Fischer method (Mettler Toledo DL32 Karl Fischer Coulometer Aqualine Electrolyte A (Fisher Scientific), Aqualine Catholyte CG A (Fischer Scientific)). Measurements were taken three times at different sample weights $(0.3$ and $0.8 \mathrm{~g})$ and averaged. After the synthesis of DES ( $2 \mathrm{~h}$ at $350 \mathrm{~K}+24 \mathrm{~h}$ of equilibration at 330 $\mathrm{K})$ the water content was determined to be $2142 \pm 123 \mathrm{ppm}$ (approximately $0.2 \mathrm{wt} \%)$. After freeze-drying $(24 \mathrm{~h})$ it had not changed significantly $(2039 \pm 16 \mathrm{ppm})$ nor had it after 2 weeks in a vial $(2214 \pm 62 \mathrm{ppm})$ despite frequent but sporadic opening and closing (which simulates the way in which the mixture was used in our other experiments). We therefore are confident that the absorption of water is not rapid on the time scale of the other measurements performed in this study and that it remains below $0.5 \mathrm{wt} \%$ in all cases. In order to minimize the variability between samples, all of the choline chloride/urea DES (molar ratio 1:2) were prepared as large stock solutions from which the surfactant solutions were subsequently made. For each of the characterization measurements presented here the $\mathrm{DES} /$ surfactant samples were prepared in advance and stored in an oven between 40 and $80{ }^{\circ} \mathrm{C}$. This was to allow for complete dissolution of the surfactant and equilibration at a temperature several degrees higher than the freezing point for a minimum of 2 to $3 \mathrm{~h}$ before use.

Methods. Surface tension measurements were made using the drop-shape-analysis method ${ }^{29}$ with a Kruss DSA100 at the Diamond Light Source. This method was used because other methods that were attempted (e.g., du Nouy ring) were found to give less consistent results. The measurement was made by withdrawing a small quantity of solution into a dispensing needle and mounting the needle on the tensiometer. A photograph was taken within 1 min of removal from the oven. Although the temperature could not be controlled, which undoubtedly introduced some uncertainty into the measurements, we believe that our method allows a self-consistent set of data to be obtained. Differential scanning calorimetry (DSC) measurements were obtained using a PerkinElmer Pyris DSC also at the Diamond Light Source.

Small-angle neutron scattering measurements were made on an LOQ instrument at the ISIS Pulsed Neutron Source, U.K. ${ }^{30}$ The data were converted from time-of-flight spectra to normalized intensity vs wavevector transfer $(Q)$ using the standard ISIS routines in the Mantid software. ${ }^{31}$ Samples were sealed in $1 \mathrm{~mm}$ cuvettes and temperature controlled at $30^{\circ} \mathrm{C}$. Samples were prepared at different contents of hydrogenated and deuterated components in the solvent or surfactant to obtain three different scattering contrasts: h-SDS in $\mathrm{d}-\mathrm{ChCl} / \mathrm{d}$-urea, $\mathrm{h}-\mathrm{SDS}$ in $\mathrm{h}-\mathrm{ChCl} / \mathrm{d}$-urea, and d-SDS in $\mathrm{h}-\mathrm{ChCl} / \mathrm{h}$-urea. Solutions were prepared at surfactant mole fractions below and above the critical micelle concentration (CMC) suggested by the surface tension measurements. The scattering from the appropriate solvent blanks 
was also measured and subtracted as a background from the scattering from the surfactant-containing samples.

The X-ray reflectivity measurements were made on beamline $\mathrm{I} 07$ at the Diamond Light Source using the double-crystal-deflector system at $12.5 \mathrm{keV}^{32}$ In this case the samples were enclosed in a helium atmosphere and contained within a temperature-controlled PTFE trough at approximately $45{ }^{\circ} \mathrm{C}$. The time between pouring and measurement was approximately $15-30 \mathrm{~min}$. Data was collected by integration over two regions of interest in a Pilatus 100k detector, one for the specular reflection and the other to approximately subtract the background. A "footprint" correction for overillumination was used, assuming a Gaussian beam profile and ignoring meniscus effects. Three attenuation regimes were collected and normalized to the critical edge.

\section{RESULTS}

Surface Tension. The surface tension curve for SDS in choline chloride/urea DES is shown in Figure 1, together with
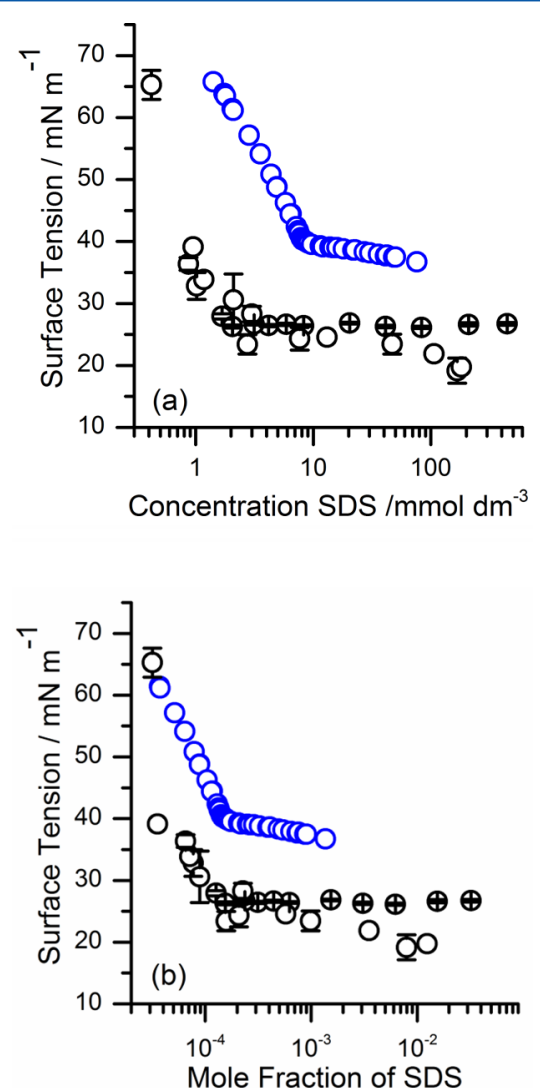

Figure 1. Surface tension of SDS in water (blue) from Elworthy and Mysels $^{24,25}$ and in the choline chloride/urea DES (black). The $x$ axis is plotted as (a) concentration or (b) mole fraction of SDS.

the literature values for SDS in water ${ }^{24,25}$ for comparison. Since our conversion to concentration is dependent on the relatively poorly defined density of the DES $\left(1.15 \mathrm{~g} \mathrm{~cm}^{-3}\right.$ determined from XRR results below and assuming that the volume of the DES is not influenced by the presence of SDS), we have plotted the data against both the mole fraction and concentration. The result clearly shows that SDS remains surface-active in the DES solutions because the surface tension shows a clear variation with concentration. Since the surface tension varies in a similar way to that seen in water, we can also infer the existence of micelles at high concentration, which we have confirmed by SANS measurements below. We have also measured the surface tension from this DES with the addition of $5 \mathrm{wt} \%$ water, but this data is not shown since no significant effect of the added water was observed. This result is consistent with the data of Pal et al., ${ }^{21}$ who showed some very low resolution SDS surface tension data for water containing choline chloride/urea solutions.

There are some interesting differences between the behavior of water and choline chloride/urea. The surface tension of the pure choline chloride/urea solution is approximately $66 \pm 1$ $\mathrm{mN} \mathrm{m} \mathrm{m}^{-1}$. This is similar to previous measurements of other DES $^{20}$ but lower than the $72 \mathrm{mN} \mathrm{m}^{-1}$ observed for water. In general, the addition of surfactant lowers the surface tension until a critical micelle concentration (CMC) is reached. This occurs at a significantly lower concentration than for the same surfactant in water. ${ }^{24,25}$ However, it is an interesting observation that when plotted on a scale of mole fraction rather than concentration the CMC is approximately the same as that of water. As far as we can tell this is not necessarily the general case for surfactants in DES. ${ }^{33}$ It is also interesting that the CMCs observed for SDS in other protic ionic liquids or nonaqueous solvents show an increase in the CMC rather than the decrease seen here (Table 1).

For SDS in the ionic liquid, 1-butyl-3-methyl imidazolium chloride (bmim- $\mathrm{Cl}$ ), although the initial surface tension is lower than that of water, the limiting surface tension above the CMC is similar. ${ }^{34}$ However, the data reported by Anderson et al. ${ }^{34}$ shows a smoother decline in surface tension with increasing concentration when compared to the discontinuity seen in our data and that commonly seen in surface tension vs concentration data for water. The lack of a discontinuity has been attributed to the formation of premicelles; ${ }^{35}$ aggregates with a small number of monomers that continuously increase in number to form larger micelles as concentration is increased, rather than the sudden transition seen in water and also in the DES studied here. We also note that in both formamide ${ }^{36}$ and bmim- $\mathrm{Cl}^{34}$ (Table 1) the aggregates observed above the CMC are described as very large, being more like phase-separated agglomerations of randomly oriented molecules than traditional micelles where the headgroups of the surfactant interact with the solvent, and the tails are sequestered in the center.

We have found that the measurement of absolute values of surface tension using our method is not repeatable to a very high accuracy $\left( \pm 1 \mathrm{mmol} \mathrm{dm}{ }^{-3}\right)$. This is most likely because of differences in temperature, atmospheric moisture, impurities, and stock solution composition. Despite this, we can reasonably assign the CMC in choline chloride/urea to $2 \pm 1 \mathrm{mmol} \mathrm{dm}^{-3}$ (mole fraction of SDS $\left(\mathrm{X}_{\mathrm{SDS}}\right)=2 \times 10^{-4} \pm 1 \times 10^{-4}$ ) for temperatures in the range of $30-50{ }^{\circ} \mathrm{C}$.

In contrast to nonionic surfactants, the solubility and formation of micelles by ionic surfactants in low-meltingpoint mixtures appear to depend sensitively on the nature of the solvent and the specific surfactant. In the case of ionic surfactants in ionic liquids, the extent of headgroup dissociation, the salts formed between the surfactant ion and components of the solvent, and the presence of trace amounts of water are all important factors determining solubility in a particular solvent. ${ }^{50}$ While aggregates of SDS are reported to form in bmimCl, ${ }^{34}$ SDS does not appear to dissolve easily in bmimPF $_{6}$ or emimTf $\mathrm{e}_{2}{ }^{50}$ This was ascribed to either the lack of hydration surrounding the SDS headgroup which prevented the solid surfactant from dissolving in $\operatorname{emimTf}_{2} \mathrm{~N}^{50}$ or the nature of the salts formed by statistical mixing (e.g., (NaTf $2 \mathrm{~N}$ and emim dodecyl sulfate in that case). For choline chloride/ urea, the salts formed by statistical mixing would be $\mathrm{NaCl}$ and 
Table 1. Literature CMC Values for SDS in a Variety of Nonaqueous Solvents Compared to the Surface Tension of the Solvent, the Kamlet Taft Solvent Parameters, and the Gordon Parameter for Each Solvent

\begin{tabular}{|c|c|c|c|c|c|c|c|c|}
\hline & \multicolumn{2}{|c|}{ SDS CMC } & \multirow[b]{2}{*}{$\underset{{ }^{\circ} \mathrm{C}}{\text { temp/ }}$} & \multicolumn{3}{|c|}{ Kamlet Taft parameters } & \multirow[b]{2}{*}{ surface tension $/ \mathrm{mN} \mathrm{m}^{-1}$} & \multirow[b]{2}{*}{$\begin{array}{c}\text { Gordon } \\
\text { Parameter } \\
(G)^{6} / \mathrm{J} \mathrm{m}^{-3}\end{array}$} \\
\hline & $\begin{array}{c}\text { conc, } \\
\text { mmol } \\
\mathrm{dm}^{-3}\end{array}$ & $\begin{array}{l}\text { mole fraction } \\
\qquad\left(\times 10^{-4}\right)^{a}\end{array}$ & & $\begin{array}{c}\alpha(\mathrm{H}- \\
\text { bond } \\
\text { donor })\end{array}$ & $\begin{array}{l}\beta \text { (H-bond } \\
\text { acceptor) }\end{array}$ & $\begin{array}{c}\pi^{*} \\
\text { polarizability }\end{array}$ & & \\
\hline \multirow[t]{2}{*}{ choline chloride/urea } & $\begin{array}{l}2 \pm 1 \text { (this } \\
\text { work) }\end{array}$ & $2 \pm 1$ & 30 & 0.675 & 0.501 & $1.226^{37}$ & $66 \pm 1$ & $1.57^{b}$ \\
\hline & $\sim 1^{21}$ & & $?$ & & & & & \\
\hline \multirow[t]{2}{*}{ water } & $8.2^{24}$ & 1.48 & 25 & 1.17 & 0.47 & 1.09 & $72.8\left(25^{\circ} \mathrm{C}\right)$ & $2.743-2.750$ \\
\hline & $8.57^{38}$ & & 35 & & & & & \\
\hline \multirow[t]{2}{*}{60 wt $\%$ glycerol in water ${ }^{39}$} & 14.14 & & 25 & 1.21 & 0.51 & 0.62 & $64.6^{40}$ (75\% glycerol, & 1.51 (glycerol \\
\hline & 17.6 & & 40 & & & & & n \\
\hline hydrazine $\left(\mathrm{H}_{4} \mathrm{~N}_{2}\right)^{38}$ & 22 & & 35 & & & & 66.67 & $2.10^{c}$ \\
\hline $\begin{array}{l}60 \text { wt } \% \text { ethylene glycol in } \\
\text { water }^{41}\end{array}$ & 24 & & 25 & 0.90 & 0.52 & 0.92 & $\begin{array}{l}50.8^{42}(0.61 \mathrm{~mol} \text { fraction } \\
\left.\text { EG in water, } 25^{\circ} \mathrm{C}\right)\end{array}$ & 1.20 (EG only) \\
\hline $\begin{array}{l}\text { 1-butyl-3-methyl imidazolium } \\
\text { chloride }(\text { bmim- } \mathrm{Cl})^{34}\end{array}$ & $48 \pm 4.4$ & 77 & $?^{d}$ & 0.32 & $0.95^{43,44}$ & $1.13^{44}$ & $48.2^{45}\left(25^{\circ} \mathrm{C}\right)$ & $0.885\left(25^{\circ} \mathrm{C}\right)$ \\
\hline formamide 23,46 & 220 & 86.9 & 60 & 0.71 & 0.48 & 0.97 & $58.2^{47}$ & $1.50-1.70$ \\
\hline
\end{tabular}

${ }^{a}$ Calculated from the literature concentration based on the literature density ${ }^{48,49}$ of the solvents in question and assuming that the dissolution of surfactant does not change the molar volume. ${ }^{b}$ Calculated using the equation given in the text, using a molar volume of $75.3 \mathrm{~cm}^{3} \mathrm{~mol}{ }^{-1} \mathrm{calculated}$ from the density $\left(1.15 \mathrm{gcm}^{-3}\right)$ and the average molar mass $\left(86.6 \mathrm{~g} \mathrm{~mol}^{-1}\right)$. ${ }^{c}$ Calculated from the surface tension, based on a density of $1.0036 \mathrm{~g}$ $\mathrm{cm}^{-338}$ and a molar mass of $32.046 \mathrm{~g} \mathrm{~mol}^{-1}$. ${ }^{\mathrm{b}} \mathrm{bmim} \mathrm{Cl}$ is solid at room temperature but is known to supercool. The temperature of the measurement is not specified in the reference.

choline-dodecyl sulfate. Previous work has shown that urea can form eutectics with alkali metal halides, with melting points between 30 and $140{ }^{\circ} \mathrm{C}, 51$ thus the dissolution of this surfactant in this DES at concentrations sufficient to allow micellization is feasible.

The formation of micelles in a particular solvent depends on both the solvent polarity and the cohesive energy density of the solvent. The cohesive energy density can be quantified using the Gordon parameter

$$
G=\frac{\gamma_{\mathrm{LV}}}{V_{\mathrm{m}}^{1 / 3}}
$$

where $\gamma_{\mathrm{LV}}$ is the liquid-air surface tension and $V_{\mathrm{m}}$ is the molar volume. ${ }^{52}$ We compare the liquid-air surface tensions, Gordon parameters, and Kamlet Taft parameters of various liquids in which SDS has been observed to form micelles (Table 1). A reduction in the cohesive energy density in general is expected to lead to an increase in the CMC, while increased solvent polarity should increase the tendency to form micelles, thus lowering the $\mathrm{CMC}^{39}$ In the case of choline chloride/urea, although the Gordon parameter is lower than that of water, it is higher than for the other solvents where micellization is reported, while the $\pi^{*}$ solvent polarizability parameter is even higher than that of water, which would lower solvent interactions with the hydrocarbon tail, possibly leading to the low CMC values measured for SDS in this solvent. Compared to the two solvents with the highest reported CMC values for SDS (which are also those for which unusually large aggregates are found), in formamide the solvent polarizability parameter is much lower than that for the choline chloride/urea DES, while in bmimCl the cohesive energy density is lower than for the DES. In each case, however, the alternate parameter is roughly similar to that of the DES, reinforcing the idea that both factors are important for micellization in a given solvent, as previously reported by others. ${ }^{39,52}$

Differential Scanning Calorimetry. We have performed a differential scanning calorimetry (DSC) analysis of the melting/ glass transition of the choline chloride/urea DES as a function of surfactant content. Our data is not sufficient to determine the order of this transition, so we have not attempted to assign it to either melting or a glass transition. This difference is a subtle one and not straightforward to distinguish in a viscous eutectic system. We believe that it is probably a glass transition, but there is some debate on this in the literature. ${ }^{53,54}$ Figure 2 shows the variation of the transition point of the DES solutions with SDS concentration (mole fraction).

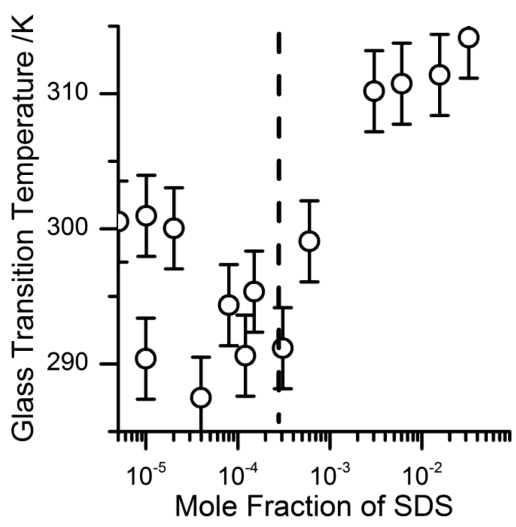

Figure 2. DSC results for solutions of SDS in choline chloride/urea. The CMC position determined above is indicated by a dashed line.

The nominal transition temperature of the pure DES is approximately $293 \pm 7 \mathrm{~K}$, which is very close to but generally slightly below room temperature in our laboratory and notably higher than the value of $285 \mathrm{~K}$ reported in the literature. ${ }^{18,20} \mathrm{At}$ low surfactant concentrations (particularly below the CMC defined above), this transition is not significantly changed. However, as the concentration increases above the CMC, there is a rapid change in the transition temperature up to $310 \pm 5 \mathrm{~K}$, where it becomes roughly constant.

Although not shown, the addition of 5 wt \% water seems to have the opposite effect to that of adding SDS by decreasing the transition temperature by about $5-10 \mathrm{~K}$. This small change 
ensures that the DES containing added water is liquid at room temperature.

Small-Angle Scattering. Figure 3(a) shows the integrated SANS intensity as a function of mole fraction of SDS
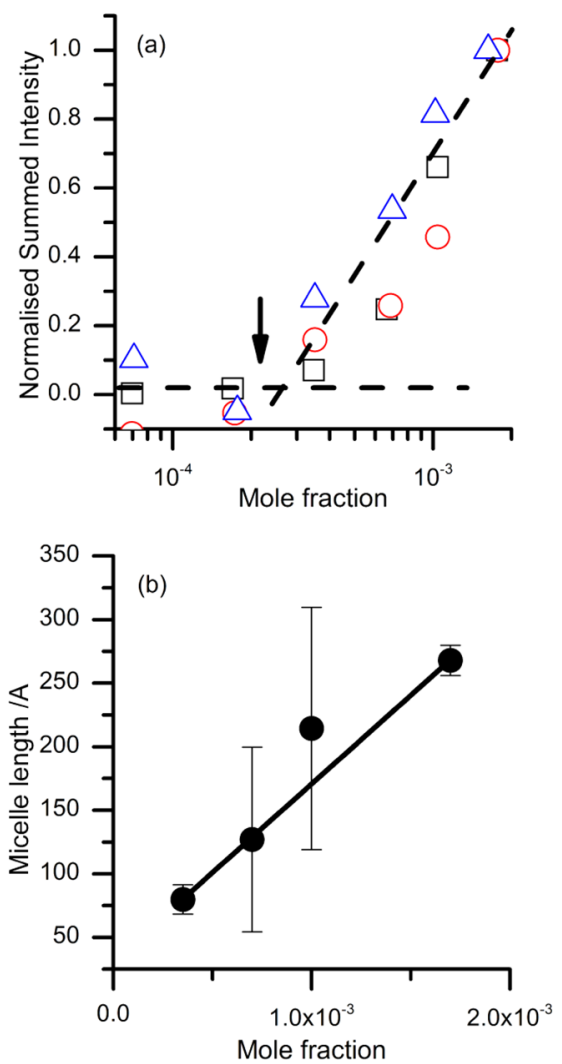

Figure 3. (a) Plot of the normalized summed scattering intensity vs mole fraction of SDS for the three contrasts measured: h-SDS in $\mathrm{d}$ $\mathrm{ChCl} / \mathrm{d}$-urea (black squares), h-SDS in h- $\mathrm{ChCl} / \mathrm{d}$-urea (red open circles), and d-SDS in h-ChCl/h-urea (blue triangles). The plots are normalized to the maximum intensity measured for each contrast, the dashed lines are a guide to the eye, and an arrow indicates the approximate CMC as determined from Figure 1. (b) Micelle length vs mole fraction of SDS, as determined by fits to the SANS data shown in Figures 4 and S1. The line is a linear fit to the data.

molecules, $X_{\mathrm{SDS}}$, for each of the measured contrasts. At low concentrations no significant scattering above the background was observed. However, above $X_{\mathrm{SDS}}=2 \times 10^{-4}$, the integrated intensity is seen to increase approximately linearly with the SDS mole fraction. We can therefore confirm that micelles exist above this mole fraction and that this is consistent with the CMC determined earlier. The scattering data from samples above the CMC is shown in Figures 4 and S1. This data has been simultaneously fitted, using data from all three contrasts, to a cylinder model $^{55}$ using the SasView data analysis software, ${ }^{56}$ and the modeled parameters are shown in Table 3. No interparticle interaction was included in the model as the volume fraction of micelles obtained was at most $0.8 \mathrm{vol} \%$. The length and radius were linked between the contrasts, with the exception of the lowest concentration. In the latter case h-SDS/ $\mathrm{DD}$ was fitted and then the parameters for length and radius were fixed for fits of the other two contrasts since their weak contrast resulted in significantly noisier data. The scatteringlength densities for each component were calculated (Table 2) and held during fitting.
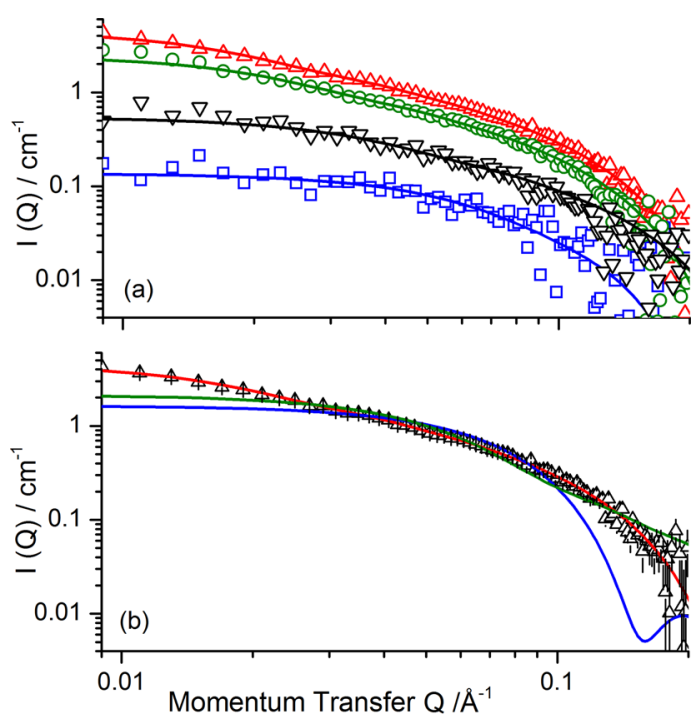

Figure 4. (a) Plots showing the scattering data (on an absolute scale) and fits for an increasing concentration of SDS for the h-SDS in the d$\mathrm{ChCl} / \mathrm{d}$-urea system. The error bars are neglected for clarity, and only data for the highest mole fractions are shown (i.e., the other samples showed no small-angle scattering). A similar plot for the other contrasts is shown in Figure S1 in the Supporting Information. The parameters used for all of the fits are listed in Table 3. All measurements were made at $303 \mathrm{~K}$. (b) Comparison of the best possible fits obtainable by assuming three possible micelle shapes. The data is the highest concentration shown in (a), and the lines correspond to fits for cylindrical (red), spherical (blue), and ellipsoidal (green) models.

Table 2. Scattering-Length Densities (SLD) Used in Fitting SANS and XRR Data

\begin{tabular}{|c|c|c|c|}
\hline & & $\begin{array}{l}\text { neutron } \mathrm{SLD}^{57} / \\
\quad \times 10^{-6} \AA^{-2}\end{array}$ & $\mathrm{X}$-ray $\mathrm{SLD} / \times 10^{-6} \AA^{-2}$ \\
\hline d-ChCl/d-urea & & 6.23 & $\begin{array}{l}10.8 \text { (fitted to critical } \\
\text { edge) }\end{array}$ \\
\hline h-ChCl/d-urea & & 3.52 & \\
\hline h-ChCl/h-urea & & 1.10 & \\
\hline d-SDS & tail & 6.25 & $\mathrm{n} / \mathrm{a}$ \\
\hline \multirow[t]{2}{*}{ h-SDS } & head & & $12.6^{58}$ \\
\hline & tail & 0.3 & $7.86^{58}$ \\
\hline
\end{tabular}

To fit this data we have used a model that assumes the micelles of SDS are cylindrical in shape. This is not the only possible shape that the micelles could adopt, but we have not been able to obtain acceptable fits to the data using different shapes. To illustrate this, Figure 4(b) shows the data from $X_{\mathrm{SDS}}$ $=1.7 \times 10^{-3}$ in $\mathrm{h}$-SDS in the $\mathrm{d}-\mathrm{ChCl} / \mathrm{d}$-urea contrast together with the best calculated fit for three possible micelle shapes: cylindrical, spherical, and ellipsoidal. It is clear from this that only the cylindrical model gives a fit that has the correct shape to match the observed data. This is in notable contrast to the behavior of SDS in water, where spherical micelles are seen at equivalently low concentrations. ${ }^{22}$

The radius of the micelles is constant within error for an average of $14.7 \pm 1.9 \AA$. This radius is determined from the scattering of only the surfactant tails because, in terms of the scattering lengths, the solvated SDS headgroups are almost indistinguishable from the solvent (at least in terms of the statistical quality of the data presented here). This distance is roughly consistent with the radius expected from dodecyl chains close to fully extended and is similar to the radius of 
Table 3. Fitting Parameters for LOQ SANS Data Shown in Figures 4 and S1

\begin{tabular}{|c|c|c|c|c|}
\hline contrast & average mole fraction of SDS $\times 10^{-4}$ & length/Å & radius $/ \AA$ & volume fraction of micelles $\times 10^{-4}$ \\
\hline $\mathrm{h}$-SDS in $\mathrm{d}-\mathrm{ChCl} / \mathrm{d}$-urea & $3.5 \pm 0.03$ & $80 \pm 12$ & $16.6 \pm 1.8$ & $5.6 \pm 0.8$ \\
\hline $\mathrm{h}$-SDS in $\mathrm{h}-\mathrm{ChCl} / \mathrm{d}$-urea & & & & $12.2 \pm 1.1$ \\
\hline $\mathrm{d}-\mathrm{SDS}$ in $\mathrm{h}-\mathrm{ChCl} / \mathrm{h}$-urea & & & & $9.7 \pm 0.6$ \\
\hline $\mathrm{h}$-SDS in $\mathrm{d}-\mathrm{ChCl} / \mathrm{d}$-urea & $6.8 \pm 0.2$ & $127 \pm 73$ & $12.0 \pm 5.3$ & $26.6 \pm 19.8$ \\
\hline $\mathrm{h}$-SDS in $\mathrm{h}$ - $\mathrm{ChCl} / \mathrm{d}$-urea & & & & $37.5 \pm 33.4$ \\
\hline $\mathrm{d}$-SDS in $\mathrm{h}-\mathrm{ChCl} / \mathrm{h}$-urea & & & & $36.6 \pm 28.4$ \\
\hline $\mathrm{h}$-SDS in $\mathrm{d}-\mathrm{ChCl} / \mathrm{d}$-urea & $10.3 \pm 0.1$ & $214 \pm 95$ & $15.1 \pm 2.3$ & $45.2 \pm 11.2$ \\
\hline $\mathrm{h}$-SDS in $\mathrm{h}-\mathrm{ChCl} / \mathrm{d}$-urea & & & & $42.7 \pm 15.8$ \\
\hline $\mathrm{d}$-SDS in $\mathrm{h}-\mathrm{ChCl} / \mathrm{h}$-urea & & & & $39.3 \pm 11.2$ \\
\hline $\mathrm{h}$-SDS in $\mathrm{d}-\mathrm{ChCl} / \mathrm{d}$-urea & $17.2 \pm 0.8$ & $268 \pm 12$ & $15.1 \pm 0.1$ & $67.2 \pm 11.1$ \\
\hline $\mathrm{h}$-SDS in $\mathrm{h}-\mathrm{ChCl} / \mathrm{d}$-urea & & & & $85.1 \pm 18.4$ \\
\hline $\mathrm{d}$-SDS in $\mathrm{h}-\mathrm{ChCl} / \mathrm{h}$-urea & & & & $52.4 \pm 11.3$ \\
\hline
\end{tabular}

spherical micelles in water. $^{22,58}$ Figure $3(\mathrm{~b})$ also shows the results of fitting the micelle length, plotted as a function of mole fraction, and indicates an approximately linear increase in the length of the micelles with increasing surfactant concentration. Our fits suggest an increase from $80 \pm 11 \AA$ at $X_{\mathrm{SDS}}=3.5 \times 10^{-4}$ to $268 \pm 12 \AA$ at $X_{\mathrm{SDS}}=1.7 \times 10^{-4}$, but the errors in these fits are substantial and it would be difficult to draw firm conclusions from them, other than to state that the micelles are clearly cylindrical and due to this are substantially larger than those seen in water. SDS in formamide ${ }^{36}$ and bmim $\mathrm{Cl}^{34}$ is also reported to form much larger aggregates than those in water, however, in those cases the aggregates reported are spherical rather than elongated as observed here, and thus they exceed the dimensions expected for the normal packing of surfactant molecules in a spherical micelle.

X-ray Reflectivity. The XRR data and corresponding fit of the pure DES are shown in Figure 5. The fits shown were calculated using Motofit, ${ }^{59}$ which uses the Abeles optical matrix method to simulate reflectometry data. The model used to fit the pure DES data has only the following variables: the SLD, the surface roughness, and a residual background level. In all of our data the background has been subtracted, so only a residual background remains due to imperfect subtraction (at $R \approx 1 \times$ $\left.10^{-10}\right)$.

The SLD of choline chloride/urea can be determined from the position of the critical edge and depends on the precise composition of the mixture (including any water that may have been absorbed from the atmosphere). We can also calculate the SLD based on the chemical formulation of the mixture and the measured density of the solution. The density of our choline chloride/urea mixture was measured to be $1.15 \pm 0.05 \mathrm{~g} \mathrm{~cm}^{-3}$. Using this density we calculate the real part of the SLD, which is $10.7 \times 10^{-6} \AA^{-2}$ at $12.5 \mathrm{keV}^{57}$ for a perfect 2:1 mixture. This is in agreement with the value of $(10.8 \pm 0.1) \times 10^{-6} \AA^{-2}$ determined from the position of the critical edge. (Note that our density is slightly different from the reported ${ }^{20}$ value of 1.25 $\mathrm{g} \mathrm{cm}^{-3}$, which would give a calculated SLD of $11.6 \times 10^{-6} \AA^{-2}$.)

The roughness of the pure DES is found to be $2.7 \pm 0.05 \AA$ and, within the resolution and reproducibility of our measurements, does not vary with the temperature or water content. This value is similar to the capillary wave roughness of water $^{60,61}(\sim 3 \AA$ at $298 \mathrm{~K})$. This roughness is mostly due to thermally induced capillary waves, and the magnitude of the roughness is related to the surface tension and indirectly to the viscosity of the liquid. As mentioned above, the surface tension of the DES is of a similar order of magnitude to that of water,
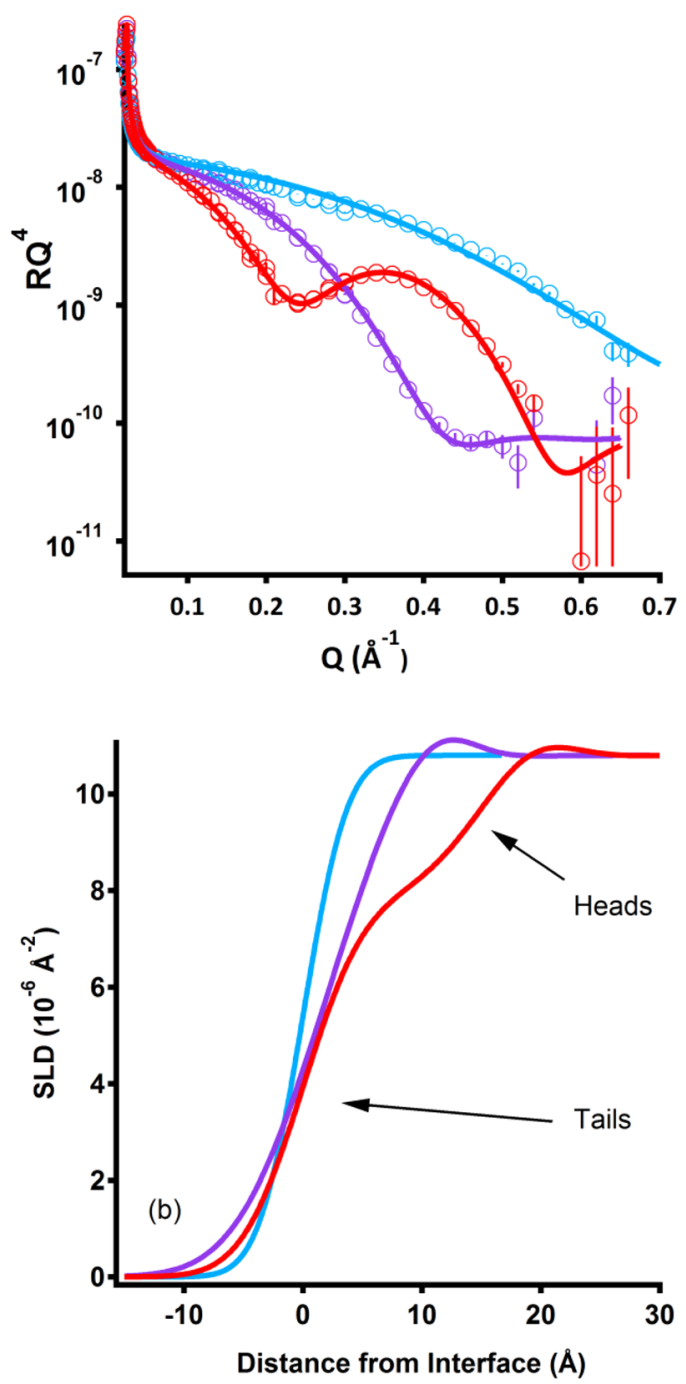

Figure 5. (a) XRR plotted on the $R^{4}$ scale. This way of displaying the data highlights the interference fringes at high $Q$ where the most significant differences in the data are visible. It also means that the background of $R=1 \times 10^{-10}$ is not directly displayed on the plot. As described in the text, an approximation to the true background has been subtracted, and the value of $1 \times 10^{-10}$ is the residual background that results from the fact that this is not a perfect subtraction. (b) Corresponding fits for pure choline chloride/urea DES (blue) and the sample containing SDS at mole fractions of $4 \times 10^{-5}$ (purple) and $6 \times$ $10^{-5}$ (red) at $303 \mathrm{~K}$. 
so it is not surprising that the measured roughness is comparable.

Figure 5 also shows the XRR data and corresponding fits for two DES containing different mole fractions of SDS (below the CMC determined above). This data is plotted on the reflectivity $\times$ momentum transfer $R^{4}$ scale since this is very sensitive to the differences observed at high angle. Qualitatively, the presence of a thin layer of SDS can simply be observed by noting the appearance of an interference fringe as the concentration is increased. The best fits to the data are obtained using a simple two-layer model which includes separate layers for the SDS head and tail groups and uses literature values for the SLDs (Table 2). This is not the only possible model that can be used to "acceptably" fit the data; an alternative single-layer model can also give good fits (Supporting Information). The SLD profiles for these models differ minimally, so we can be confident that in terms of the overall film thickness and interfacial roughness our fits are reasonably accurate but with uncertainty over the fine details of the models. We have measured XRR for a range of SDS mole fractions from $2 \times 10^{-6}$ up to the CMC at $2 \times 10^{-4}$. Broadly this data shows a trend of increasing film thickness (from $\sim 12$ to $\sim 20 \AA$ ) and interfacial roughness with increasing SDS content. Although each individual XRR measurement is good quality, there is some discrepancy between samples that we believe is due to the dynamics of surfactant adsorption after pouring. This means that the trend in increasing thickness with SDS content shows considerable scatter despite consistent sample preparation and measurement procedures. As such we cannot be confident that the measured thicknesses are at equilibrium. The kinetics of adsorption are likely to be highly dependent on the viscosity, temperature, and water content of the DES. We are therefore wary of overanalyzing the results at this stage. However, this data does clearly demonstrate that the SDS is surface-active and that the thickness of the film formed is similar to that seen on water.

\section{SUMMARY}

This study clearly demonstrates the existence of micelles in a pure DES and shows that there are considerable differences between the behavior in this DES and that seen in water. We have used both surface tension and SANS to determine the CMC to be $2 \pm 1 \mathrm{mmol} \mathrm{dm}^{-3}\left(X_{\mathrm{SDS}}=2 \times 10^{-4} \pm 1 \times 10^{-4}\right)$. Above this concentration the transition temperature of the solution increases by approximately $10 \mathrm{~K}$ and micelles are directly observed in the small-angle scattering. These micelles appear to be cylindrical rather than spherical in shape, and their length increases with increasing concentration.

As discussed earlier, $\mathrm{Pal}$ et $\mathrm{al}^{21}$ were able to show the existence of self-assembled structures in solutions of DES containing SDS and either water or cyclohexane. Only fluorescence data is given to suggest that SDS self-assembly occurs in the neat DES. Our results confirm that the observed self-assembled structures are indeed larger than the equivalent structures observed in pure water. However, in our study we have added significant detail to this generic conclusion. In particular we note that $\mathrm{Pal}$ et al. were unable to fit their SAXS data from the cyclohexane/SDS emulsions to obtain size and shape information. They specifically stated that they observed "a single broad correlation peak, followed by a $\mathrm{Q}^{-4}$ decay at higher Q values.” As far as we can tell, this is an erroneous interpretation of the data shown in Figure $6 \mathrm{~B}$ of ref 21 . Unusually, the logarithmic scale in this figure covers a range of
Q from 0.25 to $10 \AA^{-1}$, so it is not really within the range of small-angle scattering. Even accounting for a mislabeling of this axis, we believe that the "peak" observed is in fact a result of a large beam stop that truncates the data at low Q. Given these shortcomings, we cannot make a direct comparison with our data, and our results therefore represent the first quantitative observation of micelles in a pure DES.

We have also shown for the first time that the SDS remains surface-active at concentrations below the CMC. XRR measurements are consistent with a layer of surfactant between 12 and $20 \AA$ thick, which is broadly consistent with the behavior observed on water. ${ }^{27,28}$ We have also now begun a more comprehensive study of general surfactant behavior in DES systems, including cationic and nonionic surfactants in choline chloride/urea as well as other DES systems.

\section{ASSOCIATED CONTENT}

Supporting Information

The Supporting Information is available free of charge on the ACS Publications website at DOI: 10.1021/acs.langmuir.5b02596.

Details of SANS and XRR fit parameters (PDF)

\section{AUTHOR INFORMATION}

\section{Corresponding Author}

*E-mail: tom.arnold@diamond.ac.uk.

\section{Present Address}

(D.M.) School of Earth Atmospheric and Environmental Sciences and Williamson Research Centre for Molecular Environmental Science, University of Manchester, Oxford Road, Manchester M13 9PL, U.K.

\section{Author Contributions}

The manuscript was written with principal contributions from T.A., A.J.J., A.S.-F., and K.J.E. D.M. undertook some preliminary work that enabled this study, particularly early surface tension data. A.E.T. was the local contact for neutron beamtime at ISIS. All authors have given approval to the final version of the manuscript.

\section{Notes}

The authors declare no competing financial interest.

\section{ACKNOWLEDGMENTS}

We thank R. K. Thomas and P. X. Li for their assistance regarding the surface tension of SDS on water. We also thank ISIS and Diamond Light Source for awarded beamtime (experiment numbers RB1410460 and SI9748, respectively). We gratefully acknowledge DLS for funding D.M. and providing access to offline equipment and funding from the University of Bath Alumni Fund and the European Spallation Source for A.S.-F. This work benefited from use of SasView software, originally developed by the DANSE project under NSF award DMR-0520547

\section{REFERENCES}

(1) Evans, D. F.; Yamauchi, A.; Roman, R.; Casassa, E. Z. Micelle Formation in Ethylammonium Nitrate, a Low-Melting Fused Salt. J. Colloid Interface Sci. 1982, 88 (1), 89-96.

(2) Araos, M. U.; Warr, G. G. Self-Assembly of Nonionic Surfactants into Lyotropic Liquid Crystals in Ethylammonium Nitrate, a RoomTemperature Ionic Liquid. J. Phys. Chem. B 2005, 109 (30), 1427514277. 
(3) Araos, M. U.; Warr, G. G. Structure of nonionic surfactant micelles in the ionic liquid ethylammonium nitrate. Langmuir 2008, 24 (17), 9354-9360.

(4) Chen, L. G.; Bermudez, H. Solubility and Aggregation of Charged Surfactants in Ionic Liquids. Langmuir 2012, 28 (2), 1157-1162.

(5) Greaves, T. L.; Drummond, C. J. Ionic liquids as amphiphile selfassembly media. Chem. Soc. Rev. 2008, 37 (8), 1709-1726.

(6) Greaves, T. L.; Weerawardena, A.; Drummond, C. J. Nanostructure and amphiphile self-assembly in polar molecular solvents: amides and the "solvophobic effect". Phys. Chem. Chem. Phys. 2011, 13 (20), 9180-9186.

(7) Lopez-Barron, C. R.; Basavaraj, M. G.; DeRita, L.; Wagner, N. J. Sponge-to-Lamellar Transition in a Double-Tail Cationic Surfactant/ Protic Ionic Liquid System: Structural and Rheological Analysis. J. Phys. Chem. B 2012, 116 (2), 813-822.

(8) Abbott, A. P.; Boothby, D.; Capper, G.; Davies, D. L.; Rasheed, R. K. Deep Eutectic Solvents Formed between Choline Chloride and Carboxylic Acids: Versatile Alternatives to Ionic Liquids. J. Am. Chem. Soc. 2004, 126 (29), 9142-9147.

(9) Abbott, A. P.; Capper, G.; Davies, D. L.; McKenzie, K. J.; Obi, S. U. Solubility of Metal Oxides in Deep Eutectic Solvents Based on Choline Chloride. J. Chem. Eng. Data 2006, 51 (4), 1280-1282.

(10) Abbott, A. P.; Barron, J. C.; Frisch, G.; Ryder, K. S.; Silva, A. F. The effect of additives on zinc electrodeposition from deep eutectic solvents. Electrochim. Acta 2011, 56 (14), 5272-5279.

(11) Abbott, A. P.; Ttaib, K. E.; Frisch, G.; Ryder, K. S.; Weston, D. The electrodeposition of silver composites using deep eutectic solvents. Phys. Chem. Chem. Phys. 2012, 14 (7), 2443-2449.

(12) Malaquias, J. C.; Steichen, M.; Thomassey, M.; Dale, P. J. Electrodeposition of $\mathrm{Cu}-\mathrm{In}$ alloys from a choline chloride based deep eutectic solvent for photovoltaic applications. Electrochim. Acta 2013, $103(0), 15-22$.

(13) Liao, H.-G.; Jiang, Y.-X.; Zhou, Z.-Y.; Chen, S.-P.; Sun, S.-G. Shape-Controlled Synthesis of Gold Nanoparticles in Deep Eutectic Solvents for Studies of Structure-Functionality Relationships in Electrocatalysis. Angew. Chem., Int. Ed. 2008, 47 (47), 9100-9103.

(14) Abbott, A. P.; Capper, G.; Davies, D. L.; Rasheed, R. K.; Shikotra, P. Selective Extraction of Metals from Mixed Oxide Matrixes Using Choline-Based Ionic Liquids. Inorg. Chem. 2005, 44 (19), 6497-6499.

(15) Weaver, K. D.; Kim, H. J.; Sun, J.; MacFarlane, D. R.; Elliott, G. D. Cyto-toxicity and biocompatibility of a family of choline phosphate ionic liquids designed for pharmaceutical applications. Green Chem. 2010, 12 (3), 507-513.

(16) Dai, Y.; Witkamp, G.-J.; Verpoorte, R.; Choi, Y. H. Natural Deep Eutectic Solvents as a New Extraction Media for Phenolic Metabolites in Carthamus tinctorius L. Anal. Chem. 2013, 85 (13), 6272-6278.

(17) Abbott, A. P.; Cullis, P. M.; Gibson, M. J.; Harris, R. C.; Raven, E. Extraction of glycerol from biodiesel into a eutectic based ionic liquid. Green Chem. 2007, 9 (8), 868-872.

(18) Abbott, A. P.; Capper, G.; Davies, D. L.; Rasheed, R. K.; Tambyrajah, V. Novel solvent properties of choline chloride/urea mixtures. Chem. Commun. 2003, 70-71.

(19) Abbott, A. P.; Barron, J. C.; Ryder, K. S.; Wilson, D. Eutecticbased ionic liquids with metal-containing anions and cations. Chem. Eur. J. 2007, 13 (22), 6495-6501.

(20) Zhang, Q.; De Oliveira Vigier, K.; Royer, S.; Jerome, F. Deep eutectic solvents: syntheses, properties and applications. Chem. Soc. Rev. 2012, 41 (21), 7108-7146.

(21) Pal, M.; Rai, R.; Yadav, A.; Khanna, R.; Baker, G. A.; Pandey, S. Self-Aggregation of Sodium Dodecyl Sulfate within (Choline Chloride + Urea) Deep Eutectic Solvent. Langmuir 2014, 30 (44), 1319113198 .

(22) Hayter, J. B.; Penfold, J. Determination of micelle structure and charge by neutron small-angle scattering. Colloid Polym. Sci. 1983, 261 (12), 1022-1030.
(23) Perche, T.; Auvray, X.; Petipas, C.; Anthore, R. Small angle neutron scattering study of the micellization of sodium dodecyl sulfate in formamide. Langmuir 1997, 13 (6), 1475-1480.

(24) Xu, H.; Li, P. X.; Ma, K.; Thomas, R. K.; Penfold, J.; Lu, J. R. Limitations in the Application of the Gibbs Equation to Anionic Surfactants at the Air/Water Surface: Sodium Dodecylsulfate and Sodium Dodecylmonooxyethylenesulfate Above and Below the CMC. Langmuir 2013, 29 (30), 9335-9351.

(25) Elworthy, P. H.; Mysels, K. J. The surface tension of sodium dodecylsulfate solutions and the phase separation model of micelle formation. J. Colloid Interface Sci. 1966, 21 (3), 331-347.

(26) Bezzobotnov, V. Y.; Borbely, S.; Cser, L.; Farago, B.; Gladkih, I. A.; Ostanevich, Y. M.; Vass, S. Temperature and Concentration Dependence of Properties of Sodium Dodecyl Sulfate Micelles Determined from Small Angle Neutron Scattering Experiments. J. Phys. Chem. 1988, 92 (20), 5738-5743.

(27) Hines, J. D.; Thomas, R. K.; Garrett, P. R.; Rennie, G. K.; Penfold, J. Investigation of Mixing in Binary Surfactant Solutions by Surface Tension and Neutron Reflection: Anionic/Nonionic and Zwitterionic/Nonionic Mixtures. J. Phys. Chem. B 1997, 101 (45), 9215-9223.

(28) Lu, J. R.; Marrocco, A.; Su, T. J.; Thomas, R. K.; Penfold, J. Adsorption of Dodecyl Sulfate Surfactants with Monovalent Metal Counterions at the Air-Water Interface Studied by Neutron Reflection and Surface Tension. J. Colloid Interface Sci. 1993, 158 (2), 303-316.

(29) Berry, J. D.; Neeson, M. J.; Dagastine, R. R.; Chan, D. Y. C.; Taborf, R. F. Measurement of surface and interfacial tension using pendant drop tensiometry. J. Colloid Interface Sci. 2015, 454, 226.

(30) Heenan, R. K.; Penfold, J.; King, S. M. SANS at Pulsed Neutron Sources: Present and Future Prospects. J. Appl. Crystallogr. 1997, 30, 1140-1147.

(31) Arnold, O.; Bilheux, J. C.; Borreguero, J. M.; Buts, A.; Campbell, S. I.; Chapon, L.; Doucet, M.; Draper, N.; Ferraz Leal, R.; Gigg, M. A.; Lynch, V. E.; Markvardsen, A.; Mikkelson, D. J.; Mikkelson, R. L.; Miller, R.; Palmen, K.; Parker, P.; Passos, G.; Perring, T. G.; Peterson, P. F.; Ren, S.; Reuter, M. A.; Savici, A. T.; Taylor, J. W.; Taylor, R. J.; Tolchenov, R.; Zhou, W.; Zikovsky, J. Mantid-Data analysis and visualization package for neutron scattering and SR experiments. Nucl. Instrum. Methods Phys. Res., Sect. A 2014, 764 (0), 156-166.

(32) Arnold, T.; Nicklin, C. L.; Rawle, J.; Sutter, J.; Bates, T.; Nutter, B.; McIntyre, G.; Burt, B. Implementation of a beam deflection system for studies of liquid interfaces on Beamline I07 at Diamond. J. Synchrotron Radiat. 2012, 19 (3), 408-416.

(33) Arnold, T.; Edler, K. J.; Jackson, A. J.; Sanchez-Fernandez, A., malic acid - choline chloride. To be submitted for publication.

(34) Anderson, J. L.; Pino, V.; Hagberg, E. C.; Sheares, V. V.; Armstrong, D. W. Surfactant solvation effects and micelle formation in ionic liquids. Chem. Commun. 2003, 19, 2444-2445.

(35) Evans, D. F.; Wennerström, H. The Colloidal Domain: Where Physics, Chemistry, Biology, and Technology Meet, 2nd ed.; Wiley-VCH: New York, 1999.

(36) Pan, A.; Naskar, B.; Prameela, G. K. S.; Phani Kumar, B. V. N.; Aswal, V. K.; Bhattacharya, S. C.; Mandal, A. B.; Moulik, S. P. Micellization and related behavior of sodium dodecylsulfate in mixed binary solvent media of tetrahydrofuran $(\mathrm{Tf})$ and formamide $(\mathrm{Fa})$ with water: a detailed physicochemical investigation. Soft Matter 2014, 10 (31), 5682-5694.

(37) Pandey, A.; Rai, R.; Pal, M.; Pandey, S. How polar are choline chloride-based deep eutectic solvents? Phys. Chem. Chem. Phys. 2014, 16 (4), 1559-1568.

(38) Ramadan, M. S.; Evans, D. F.; Lumry, R. Why micelles form in water and hydrazine. A reexamination of the origins of hydrophobicity. J. Phys. Chem. 1983, 87 (22), 4538-4543.

(39) Ruiz, C. C.; Díaz-López, L.; Aguiar, J. Micellization of Sodium Dodecyl Sulfate in Glycerol Aqueous Mixtures. J. Dispersion Sci. Technol. 2008, 29 (2), 266-273.

(40) Baldelli, S.; Schnitzer, C.; Shultz, M. J.; Campbell, D. J. Sum Frequency Generation Investigation of Glycerol/Water Surfaces. J. Phys. Chem. B 1997, 101 (23), 4607-4612. 
(41) Gracie, K.; Turner, D.; Palepu, R. Thermodynamic properties of micellization of sodium dodecyl sulfate in binary mixtures of ethylene glycol with water. Can. J. Chem. 1996, 74 (9), 1616-1625.

(42) Hoke, B. C.; Chen, J. C. Binary aqueous-organic surface tension temperature dependence. J. Chem. Eng. Data 1991, 36 (3), 322-326.

(43) Lungwitz, R.; Friedrich, M.; Linert, W.; Spange, S. New aspects on the hydrogen bond donor (HBD) strength of 1-butyl-3methylimidazolium room temperature ionic liquids. New J. Chem. 2008, 32 (9), 1493-1499.

(44) Lungwitz, R.; Strehmel, V.; Spange, S. The dipolarity/ polarisability of 1-alkyl-3-methylimidazolium ionic liquids as function of anion structure and the alkyl chain length. New J. Chem. 2010, 34 (6), 1135-1140.

(45) Ghatee, M. H.; Zolghadr, A. R. Surface tension measurements of imidazolium-based ionic liquids at liquid-vapor equilibrium. Fluid Phase Equilib. 2008, 263 (2), 168-175.

(46) Rico, I.; Lattes, A. Formamide, a water substitute. 12. Krafft temperature and micelle formation of ionic surfactants in formamide. $J$. Phys. Chem. 1986, 90 (22), 5870-5872.

(47) Wärnheim, T.; Jönsson, A. Phase diagrams of alkyltrimethylammonium surfactants in some polar solvents. J. Colloid Interface Sci. 1988, 125 (2), 627-633.

(48) Cases, A. M.; Gómez Marigliano, A. C.; Bonatti, C. M.; Sólimo, H. N. Density, Viscosity, and Refractive Index of Formamide, Three Carboxylic Acids, and Formamide + Carboxylic Acid Binary Mixtures. J. Chem. Eng. Data 2001, 46 (3), 712-715.

(49) Huddleston, J. G.; Visser, A. E.; Reichert, W. M.; Willauer, H. D.; Broker, G. A.; Rogers, R. D. Characterization and comparison of hydrophilic and hydrophobic room temperature ionic liquids incorporating the imidazolium cation. Green Chem. 2001, 3 (4), $156-164$.

(50) Fletcher, K. A.; Pandey, S. Surfactant Aggregation within RoomTemperature Ionic Liquid 1-Ethyl-3-methylimidazolium Bis(trifluoromethylsulfonyl)imide. Langmuir 2004, 20 (1), 33-36.

(51) Gambino, M.; Bros, J. P. Capacite calorifique de l'uree et de quelques melanges eutectiques a base d'uree entre 30 et $140^{\circ} \mathrm{C}$. Thermochim. Acta 1988, 127 (0), 223-236.

(52) Greaves, T. L.; Drummond, C. J. Solvent nanostructure, the solvophobic effect and amphiphile self-assembly in ionic liquids. Chem. Soc. Rev. 2013, 42 (3), 1096-1120.

(53) Francisco, M.; van den Bruinhorst, A.; Kroon, M. C. LowTransition-Temperature Mixtures (LTTMs): A New Generation of Designer Solvents. Angew. Chem., Int. Ed. 2013, 52 (11), 3074-3085.

(54) Morrison, H. G.; Sun, C. C.; Neervannan, S. Characterization of thermal behavior of deep eutectic solvents and their potential as drug solubilization vehicles. Int. J. Pharm. 2009, 378 (1-2), 136-139.

(55) Pedersen, J. S. Analysis of small-angle scattering data from colloids and polymer solutions: Modeling and least squares fitting. Adv. Colloid Interface Sci. 1997, 70, 171-210.

(56) SasView. http://www.sasview.org/.

(57) Kienzle, P. NIST SLD Calculator. http://www.ncnr.nist.gov/ resources/activation/ , 2015, accessed on 18/06/2015. It uses neutron cross sections from Rauch, H.; Waschkowski, W. Neutron Scattering Lengths in ILL Neutron Data Booklet, 2nd ed.; Dianoux, A.-J., Lander, G., Eds.; Old City Publishing: Philadelphia, PA, 2003; pp 1.1-1-1.117.

(58) Lin, J.-M.; Lin, T.-L.; Jeng, U. S.; Huang, Z.-H.; Huang, Y.-S. Aggregation structure of Alzheimer amyloid-[small beta](1-40) peptide with sodium dodecyl sulfate as revealed by small-angle X-ray and neutron scattering. Soft Matter 2009, 5 (20), 3913-3919.

(59) Nelson, A. Co-refinement of multiple-contrast neutron/X-ray reflectivity data using MOTOFIT. J. Appl. Crystallogr. 2006, 39, 273276.

(60) Braslau, A.; Pershan, P. S.; Swislow, G.; Ocko, B.; Als-Nielsen, J. Capillary waves on the surface of simple liquids measured by $\mathrm{x}$-ray reflectivity. Phys. Rev. A: At., Mol., Opt. Phys. 1988, 38, 2457.

(61) Pershan, P. S.; Schlossman, M. L. Liquid Surfaces and Interfaces; Cambridge University Press: 2012. 